\title{
Research on Cooperative Game and Dynamic Mechanism of Industry-University-Research Synergistic Innovation
}

\author{
Liu Yang \\ Wuhan University of Technology \\ Wuhan, China \\ 18202769027@163.com
}

\author{
Renyan $\mathrm{Mu}$ \\ Wuhan University of Technology \\ Wuhan, China \\ 28968027@qq.com
}

\begin{abstract}
Innovation is the main engine of economic development. Building the industry-university-research synergistic innovation mechanism is an important measure to promote the implementation of innovation-driven development strategy. Based on the game theory, this thesis studies the cooperation strategies of industry, university and research in the process of synergistic innovation, constructs the payment functions of the four cooperation strategies, and analyzes the results of different strategies. From both the internal and external dimensions, this thesis further explores the dynamic factors and their mechanism of industry-university-research synergistic innovation and puts forward three targeted suggestions which are improving the distribution of benefits and risks, strengthening the guiding role of government and improving the intermediary service system.
\end{abstract}

Keywords-enterprises, universities and institutes; synergistic Innovation; game theory; dynamic mechanism

\section{INTRODUCTION}

Innovative activities have typical features with high devotion, long cycle and high risk. In the process of innovation, due to the limited innovation fund, the low technological level and the inefficient ability of innovation achievements marketing, the independent innovation often undertakes larger risk pressure. However, the industry-university-research synergistic innovation can reduce and share $R \& D$ risks and costs to the utmost extent through the resource complementarity among different innovators. It is an effective ways to speed up the integration of innovative elements and improve the efficiency of organizational innovation.

In this case, more and more scholars study the industryuniversity-research synergistic innovation. Peter Gloor [1] puts forward the concept of synergistic innovation for the first time, which is the process of Self-motivated individuals forming a network group and a collective vision, using the network to exchange ideas, information and working conditions to achieve the common goal. Rad [2] regards the industry-universityresearch synergistic innovation as a complex economic system from the perspective of overall system. On the model of industry-university-research synergistic innovation, Branco [3] believes that the co-construction of solid type industryuniversity-research collaboration model is conducive to stabilizing the main cooperative relationship and coordinating

Supported by "the National Social Science Foundation of China" (Grant No.17BGL209) and "the Fundamental Research Funds for the Central Universities”. innovative resources. According to the close degree, Wang Zhangbao [4] divides the models of synergistic innovation into Project-based type, co-constructed type, solid type and virtual type. On the motivation mechanism of industry-universityresearch synergistic innovation, Veugcler [5] argues that knowledge heterogeneity is the fundamental driving force and Fang Wei et al. [6] verify the positive effects of attributes, communication and environment on synergistic innovation through literature research and structural equation modeling.

Overall, the research on industry-university-research synergistic innovation is still in the primary stage and many specific issues are yet to be further explored. This article intends to demonstrate the necessity of synergistic innovation of industry, university and research through the cooperative game model, and further explore the dynamic factors and their mechanism.

\section{COOPERATIVE GAME ANALYSIS OF INDUSTRY-UNIVERSITY- RESEARCH SYNERGISTIC INNOVATION}

In the process of synergistic innovation, Universities, institutes and enterprises are the main participants. Giving that universities and institutes take knowledge and technology as their comparative advantages and play the similar roles, the two parties in the game are enterprises and universitiesinstitutes.

Based on that, this thesis will establish four different cooperative game models of enterprises and universitiesinstitutes, study the results of different game strategies in the process of synergistic innovation, and verify the optimal strategies of the synergistic innovation through constructing and analyzing the payment functions of different cooperation strategies.

\section{A. Basic assumptions of establishing cooperative game model}

Hypothesis 1: Enterprises and universities-institutes are the only two main subjects. It is assumed that the government does not participate in the cooperative game.

Hypothesis 2: Both of enterprises and universities-institutes are the rational-economic man. According to the rational economic man hypothesis, the goal of two parties is to achieve maximum profit. 
Hypothesis 3: Complete Information. Both enterprises and universities-institutes are aware of each other's game behaviors, the probability of making some decisions and its gains and losses.

Based on the above basic assumptions, this thesis establishes the game pay-off matrix of enterprises and universities-institutes in the process of synergistic innovation (Table 1).

TABLE I. THE GAME PAY-OFF MATRIX OF ENTERPRISES AND UNIVERSITIES-INSTITUTES

\begin{tabular}{|c|c|c|c|}
\hline \multirow{3}{*}{ Enterprises } & \multicolumn{3}{|c|}{ Universities-institutes } \\
\cline { 2 - 4 } & & Cooperation & Quit \\
\cline { 2 - 4 } & Cooperation & $(+1,+1)$ & $(-1,0)$ \\
\cline { 2 - 4 } & Quit & $(0,-1)$ & $(-1,-1)$ \\
\hline
\end{tabular}

It can be stipulated that in the game pay-off matrix that each additional unit of enterprises payment $\mathrm{Z}$ and universitiesinstitutes payment $Q$ raising a unit of income is expressed as +1 , otherwise expressed as -1 . If neither the raising nor the loss of income is expressed as 0 . Enterprises and universities-institutes have a significant impact on cooperative innovation projects and their behaviors will affect their own gains and losses, which constitute a whole interest, the Union Pay $\mathrm{W}=\mathrm{Z}+\mathrm{Q}$.

According to the above game pay-off matrix, only when enterprises and universities-institutes make the decision to keep cooperation simultaneously, can each of them obtain a unit of income, and the Union Pay reach the maximum, that is $\mathrm{W}=\mathrm{Z}+\mathrm{Q}=+2$.

In order to further demonstrate the optimal strategy of the synergistic innovation, this article will build the payment functions of enterprises and universities-institutes and the union payment functions of four cooperative game strategies.

\section{B. Payment Function Construction}

1) Payment Function of Universities-institutes:

$$
\begin{aligned}
f_{1}\left(w_{1}, w_{2}\right) & =\zeta \cdot \gamma_{1}\left(w_{1}\right) \cdot \gamma_{2}\left(w_{2}\right) \cdot q-c_{1}\left(w_{1}\right) \\
& =q \zeta\left[1-\left(w_{1}+1\right)^{-\alpha_{1}}\right]\left[1-\left(w_{2}+1\right)^{-\alpha_{2}}\right]-\beta_{1} w_{1}^{\gamma_{1}},
\end{aligned}
$$

2) Payment Function of Enterprises:

$$
\begin{aligned}
f_{2}\left(w_{1}, w_{2}\right) & =\zeta \cdot \gamma_{1}\left(w_{1}\right) \cdot \gamma_{2}\left(w_{2}\right) \cdot(1-q)-c_{2}\left(w_{2}\right) \\
& =(1-q) \zeta\left[1-\left(w_{1}+1\right)^{-\alpha_{1}}\right]\left[1-\left(w_{2}+1\right)^{-\alpha_{2}}\right]-\beta_{2} w_{2}^{\gamma_{2}},
\end{aligned}
$$

3) Payment Function of the Union Pay:

$$
\begin{aligned}
f_{1,2}\left(w_{1}, w_{2}\right) & =f_{1}\left(w_{1}, w_{2}\right)+f_{2}\left(w_{1}, w_{2}\right) \\
& =\zeta\left[1-\left(w_{1}+1\right)^{-\alpha_{1}}\right]\left[1-\left(w_{2}+1\right)^{-\alpha_{2}}\right]-\beta_{1} w_{1}^{\gamma_{1}}-\beta_{2} w_{2}^{\gamma_{2}},
\end{aligned}
$$

In the above formulas, $W_{1}$ and $W_{2}$ represent the standard workload of universities-institutes and enterprises putting into the cooperative innovation project, which is continuous $\left(W_{1} \geq 0\right.$ and $W_{2} \geq 0$ ). Due to diminishing returns and rising costs, it is assumed that the upper limit of the universities-institutes' work is $W_{1}{ }^{u p}$ and the enterprises' is $W_{2}{ }^{u p} ; \gamma$ represents the value that universities-institutes and enterprises cooperation projects can achieve after they put into their workloads $(\gamma>0) ; \xi$ represents the upper limit of the value of the project; The ratio of universities-institutes accessing to the project income distribution is q, then enterprises will be $1-\mathrm{q}(0<\mathrm{q}<1)$.

\section{Payment function analysis}

1) The necessary and sufficient conditions for the optimal union payment

In the process of synergistic innovation, the goal of universities-institutes and enterprises are achieving the maximum value of the union payoff function, which is equivalent to solving the optimization problem:

$$
\begin{aligned}
& \operatorname{Max}_{0 \leq w_{1} \leq w_{1}^{\text {up }}} f_{1,2}\left(w_{1}, w_{2}\right) \\
& 0 \leq w_{2} \leq w_{2}^{\text {up }} \\
& =\operatorname{Max}_{\substack{0 \leq w_{1} \leq w_{1}^{\text {up }} \\
0 \leq w_{2} \leq w_{2}^{\text {up }}}} \zeta\left[1-\left(w_{1}+1\right)^{-\alpha_{1}}\right]\left[1-\left(w_{2}+1\right)^{-\alpha_{2}}\right]-\beta_{1} w_{1}^{\gamma_{1}}-\beta_{2} w_{2}^{\gamma_{2}},
\end{aligned}
$$

Through taking a derivative of $W_{1}$ and $W_{2}$, we can get the necessary and sufficient conditions that the Union Pay function can achieve the maximum value in the situation $\left(W_{1}\right.$, $\left.\max , W_{2, \max }\right)$ :

$$
\begin{aligned}
& \frac{C_{1}^{\prime}\left(w_{1, \max }\right)}{\gamma_{1}^{\prime}\left(w_{1, \max }\right)}=\zeta \cdot \gamma_{2}\left(w_{2, \max }\right), \\
& \frac{C_{2}^{\prime}\left(w_{2, \max }\right)}{\gamma_{2}^{\prime}\left(w_{2, \max }\right)}=\zeta \cdot \gamma_{2}\left(w_{1, \max }\right),
\end{aligned}
$$

2) The stability analysis of the optimal solution of Union Pay function

Under the condition of complete information, universitiesinstitutes and enterprises will agree that the situation $\left(W_{1, \max }\right.$, $W_{2 \text {, max }}$ ) is the optimal solution of the Union Pay function.

Firstly, assuming that universities-institutes have given up the cooperative game in order to achieve the best interests of its own: $W_{1}=W_{1 \text {, new }}$, and suppose $W_{1 \text {, new }}>W_{1 \text {, max }}$. Then:

$$
\begin{aligned}
f_{1}\left(w_{1, \max }, w_{2, \max }\right) & =q \zeta \cdot \gamma_{1}\left(w_{1, \max }\right) \cdot \gamma_{2}\left(w_{2, \max }\right)-c_{1}\left(w_{1, \max }\right) \\
& \leq q \zeta \cdot \gamma_{1}\left(w_{1, \text { new }}\right) \cdot \gamma_{2}\left(w_{2, \text { new }}\right)-c_{1}\left(w_{1, \text { new }}\right), \\
& =f_{1}\left(w_{1, \text { new }}, w_{2, \text { new }}\right)
\end{aligned}
$$

And

$$
\begin{aligned}
f_{1,2}\left(w_{1, \text { max }}, w_{2, \text { max }}\right) & =f_{1}\left(w_{1, \text { max }}, w_{2, \text { max }}\right)+f_{2}\left(w_{1, \text { max }}, w_{2, \text { max }}\right) \\
& \square f_{1}\left(w_{1, \text { new }}, w_{2, \text { max }}\right)+f_{2}\left(w_{1, \text { new }}, w_{2, \text { max }}\right), \\
& =f_{1,2}\left(w_{1, \text { new }}, w_{2, \text { max }}\right)
\end{aligned}
$$

However, this formula is contradictory to " $\left(W_{1, \max }, W_{2, \max }\right)$ is the optimal solution of the Union Pay function". Therefore, the new strategy adopted by the government can only be:

$$
W_{1}=W_{1, \text { new }} \text { and } W_{1, \text { new }}<W_{1, \max }
$$

Also, if enterprises give up and take a new strategy $W_{2}=W_{2}$, new, then there must be: 


$$
W_{2}=W_{2, \text { new }} \text { and } W_{2, \text { new }}<W_{2, \max }
$$

It can be concluded that, when universities-institutes or enterprises decide to abandon the cooperative game and reduce the work load, the other party earnings will be reduced.

Finally, if both universities-institutes and enterprises decided to give up the cooperation, and take $W_{1 \text {, new }}$ and $W_{2 \text {, new }}$ as their new strategy. Then the conclusion obtained from the previous is:

$$
\begin{aligned}
f_{1}\left(w_{1, \text { new }}, w_{2, \text { new }}\right) & =q \zeta \cdot \gamma_{1}\left(w_{1, \text { new }}\right) \cdot \gamma_{2}\left(w_{2, \text { new }}\right)-c_{1}\left(w_{1, \text { new }}\right) \\
& <q \zeta \cdot \gamma_{1}\left(w_{1, \text { new }}\right) \cdot \gamma_{2}\left(w_{2, \text { new }}\right)-c_{1}\left(w_{1, \text { new }}\right), \\
& =f_{1}\left(w_{1, \text { new }}, w_{2, \text { new }}\right) \\
f_{2}\left(w_{1, \text { new }}, w_{2, \text { new }}\right) & =(1-q) \zeta \cdot \gamma_{1}\left(w_{1, \text { new }}\right) \cdot \gamma_{2}\left(w_{2, \text { new }}\right)-c_{2}\left(w_{2, \text { new }}\right) \\
& <(1-q) \zeta \cdot \gamma_{1}\left(w_{1, \text { new }}\right) \cdot \gamma_{2}\left(w_{2, \text { new }}\right)-c_{2}\left(w_{2, \text { new }}\right), \\
& =f_{2}\left(w_{1, \text { new }}, w_{2, \text { new }}\right)
\end{aligned}
$$

In that case, universities-institutes and enterprises as well as their union gains will suffer losses.

\section{The result analysis of cooperative game model}

According to the above analysis, the cooperative game between universities-institutes and enterprises has union payment and it can reach the maximum. In the process of the cooperative innovation project, if one of the parties withdraws unilaterally while the other is still operating, the observing party will suffer a loss and the union payment will also decrease; If both parties withdraw, the profits of the two parties and their union gains will inevitably decrease. In other words, the cooperative innovation project can achieve the maximization of returns only when both universities-institutes and enterprises decide to maintain cooperation, which shows the important value of establishing industry-university-research synergistic innovation mechanism.

\section{DYNAMIC MECHANISM OF INDUSTRY-UNIVERSITY- RESEARCH SYNERGISTIC INNOVATION}

\section{A. Analysis on dynamic factors of Industry-university-research Synergistic Innovation}

Based on the essential elements of innovation activities, this thesis analyzes the dynamic factors of industry-university-

\begin{tabular}{|c|c|c|}
\hline \multicolumn{3}{|c|}{ Internal Factors } \\
\hline Profit & Perfect: Driving Force & A $\quad$ perfect PDM will increase \\
\hline $\begin{array}{l}\text { Distribution } \\
\text { Mechanism } \\
\text { (PDM) }\end{array}$ & Imperfect: Resistance & $\begin{array}{l}\text { cooperative initiative; otherwise, it } \\
\text { won't. }\end{array}$ \\
\hline Risk & Perfect: Driving Force & RSM will reduce \\
\hline Sharing & Imperfect: Resistance & innovation risks and promote the \\
\hline $\begin{array}{l}\text { Mechanism } \\
\text { (RSM) }\end{array}$ & & ation; otherwise, \\
\hline
\end{tabular}
research synergistic innovation from the internal and external dimensions and studies their mechanism and effect from a system perspective. The dynamic factors are as follows (Table 2):

TABLE II. DYNAMIC FACTORS OF SYNERGISTIC INNOVATION AND THEIR MECHANISM



According to the above table, under certain circumstances, the dynamic factors that affect the synergistic innovation can be transformed from positive driving force into reverse resistance. Take innovation elements as an example. During the process of synergistic innovation, enough manpower, capital and material resources input has a positive effect on the cooperative innovation projects. Otherwise, if innovation elements are deficient, they will hinder the progress of collaborative innovation activities.

\section{B. Evaluation Model of Dynamic Mechanism}

Considering the combined effect of dynamic factors, this thesis puts forward a mathematical evaluation model of industry-university-research synergistic innovation.

Marking the total value of dynamic factors of industryuniversity-research synergistic innovation as $\mathrm{F}$; the symbols and coefficients of each dynamic factor is shown in Table 3.

TABLE III. ANALYSIS OF EVALUATION MODEL OF DyNAMIC MECHANISM

\begin{tabular}{|c|c|c|}
\hline No. & Dynamic Factor & Coefficient \\
\hline 1 & Profit Distribution Mechanism(d1) & $\lambda 1$ \\
\hline 2 & Risk Sharing Mechanism(d2) & $\lambda 2$ \\
\hline 3 & Innovation Elements(d3) & $\lambda 3$ \\
\hline 4 & Technology Potential Differences(d4) & $\lambda 4$ \\
\hline 5 & Policy Orientation(d5) & $\lambda 5$ \\
\hline 6 & Market Demand(d6) & $\lambda 6$ \\
\hline 7 & Intermediary Service(d7) & $\lambda 7$ \\
\hline
\end{tabular}

Giving that the influence of various dynamic factors on the synergistic innovation is inconsistent, the value range of coefficient $(\lambda)$ is specified as $[-1,0) \cup(0,1]$. In the process of synergistic innovation, the absolute value of a dynamic factor's coefficient can be weighted by expert scoring, factor comparison and other methods. If the dynamic factor has a positive driving effect, the value is positive, otherwise, it is negative. Based on the above provisions, this thesis gives the following evaluation model of the dynamic mechanism: 


$$
\begin{aligned}
& F=\sum_{i=1}^{7} \lambda_{i} d_{i} \\
& =\lambda_{1} d_{1}+\lambda_{2} d_{2}+\lambda_{3} d_{3}+\lambda_{4} d_{4}+\lambda_{5} d_{5}+\lambda_{6} d_{6}+\lambda_{7} d_{7}
\end{aligned}
$$

\section{CONCLUSION AND SUGGESTION}

\section{A. Main Conclusions}

This thesis constructs the payment functions of four cooperation strategies between universities-institutes and enterprises on the basis of game theory and the existing theoretical framework of industry-university-research synergistic innovation, and analyzes the stability of the optimal solution of the union payment function. The results show that only when universities-institutes and enterprises make decision to maintain cooperation, can both parties benefit and the union payment reach the maximum, making full use of the synergistic innovation.

Based on that, this thesis further explores the dynamic factors that affect the synergistic innovation and their mechanism, and constructs the mathematical model of dynamic mechanism. The dynamic mechanism mainly includes three internal factors such as profit distribution mechanism, risk sharing mechanism, innovation elements and technical potential differences, as well as three external factors such as policy orientation, market demand and intermediary services. Under certain conditions, a specific factor may play a role of positive driver, but also the role of reverse obstruction. Therefore, the key of strengthening industry-universityresearch synergistic innovation is how to give full play to the positive driving force of these dynamic factors.

\section{B. Countermeasures and Suggestions}

1) Improving the profit distribution and risk sharing mechanism

On the one hand, following the principle of matching profit and risk, it is necessary to establish the scientific profit and risk evaluation mechanism and take it as the standards of profit distribution and risk sharing among industry, university and research. On the other hand, it is important to introduce the third-party supervisory bodies to safeguard the fairness of the mechanism.

\section{2) Strengthening the guiding role of government}

The government needs to step up its efforts to help and encourage industry, university, research and other parties to speed up the construction of innovative cooperative relations through the establishment of synergistic innovation risk funds and incentive funds. In addition, the government should set up a cooperation platform and create a good environment for synergistic innovation.

\section{3) Perfecting the intermediary service system}

Improving financial service system to broaden financing channels for industry-university-research synergistic innovation; improving the third party guarantee service system to reduce the risk of innovation; improving the information service system to establish public information platform of market requirements and knowledge and technology supply.

\section{ACKNOWLEDGMENT}

The author acknowledges the financial support from the National Social Science Foundation of China (Grant No.17BGL209) and the Fundamental Research Funds for the Central Universities.

\section{REFERENCES}

[1] Peter Gloor. Swarm. Creativity: Competitive Advantage through Collaborative Innovation Networks [M]. Oxford: Oxford University Press, 2005.

[2] Rad M M. Seyedesfahani M M. Jalilvand M R. An effective collaboration model between industry and university based on the theory of self-organization: A system dynamics model [J].Journal of Science \& Technology Policy Management, 2015, 6(1): 2-24.

[3] Ponomariov B. Government-sponsored university-industry collaboration and the production of nanotechnology patents in US universities [J]. The Journal of Technology Transfer, 2013, 38(6):749-767

[4] Wang Zhangbao, Han Yizhou, Hong Tianyu. Analysis on the Industryuniversity-research Synergistic Innovation Model and their Advantages and Disadvantages [J]. Science \& Technology Progress and Policy, 2015(2): 24-29. (In Chinese)

[5] Pierre V. Identifying collaborative innovation capabilities within know ledge-intensive environments: insights from the ARPA NET project [J]. European Journal of Innovation Management, 2012(1): 152-155.

[6] Fang Wei, NIU Tingting. Study on the Dynamic Evolution of Stakeholders' Relationship Networks of Industry, University and Institutes [J]. Studies in Science of Science, 2017, 35(5): 746-753. (In Chinese) 